\title{
Effect of pH on DDT degradation in aqueous solution using bimetallic $\mathrm{Ni} / \mathrm{Fe}$ nanoparticles
}

\author{
Hua Tian, Jinjun Li, Zhen Mu, Landong Li, Zhengping Hao* \\ Research Center for Eco-Environmental Sciences, Chinese Academy of Sciences, Beijing 100085, China
}

\section{A R T I C L E I N F O}

\section{Article history:}

Received 4 June 2008

Received in revised form

20 November 2008

Accepted 25 November 2008

\section{Keywords:}

DDT

Degradation

$\mathrm{Ni} / \mathrm{Fe}$ bimetal

Nanoparticle

\begin{abstract}
A B S T R A C T
In this study, bimetallic $\mathrm{Ni} / \mathrm{Fe}$ nanoparticles were prepared and the ability of this material to degrade DDT in aqueous solution was investigated at room temperature. Besides comparing the degradation rates of DDT using monometallic zero-valent iron and bimetallic Ni/Fe, batch investigations with bimetallic $\mathrm{Ni} / \mathrm{Fe}$ nanoparticles were conducted to explore the influence of $\mathrm{pH}$ value on the degradation rate of DDT in aqueous solution. Results indicate that weakly acidic $(4 \leq \mathrm{pH}<7)$ or alkaline reaction $(7<\mathrm{pH} \leq 10)$ conditions afford faster degradation rates, whereas higher or lower $\mathrm{pH}$ inhibits the DDT degradation. In addition, the DDT degradation exhibits an interesting pathway and mechanism at higher $\mathrm{pH}$ value $(\mathrm{pH}>10)$ in reaction solution. In strong alkaline solution, the DDT degradation becomes slow but is not quenched. The electron transfer for DDT degradation is enhanced by creating numerous galvanic cells under the Ni catalysis, and promotes the dehydrochlorination reaction. The hydrodechlorination reaction in alkaline condition is also unbroken. This phenomenon is quite different from those reported in other studies previously.
\end{abstract}

(c) 2008 Elsevier B.V. All rights reserved.

\section{Introduction}

DDT (1,1,1-trichloro-2,2'bis(p-chlorophenyl)ethane) has been used extensively since the 1940 s as a pesticide for agricultural purpose and public health to check malaria and other mosquito borne diseases (yellow fever, encephalitis). But its persistence, bioaccumulation, toxicity and long-range atmospheric transport bring many risks to human health and environment. Although it has been regulated under the Stockholm Convention [1], and banned by many countries in the 1970s, DDT and its metabolites are still found at numerous sites in the world [2-4].

Over the past two decades, a number of methods for the DDT degradation have been developed, including biological treatments [5], photochemical reactions [6] and metal-catalyzed reactions [7]. In recent years, a promising technology is the use of zero-valent metals, such as Fe and $\mathrm{Zn}$. This technology has many advantages in the treatment of water and soil DDT contaminates, including free of environmental pollution and high efficiency by direct injection of zero-valent metal nanoparticles into contaminant source zones. However, the use of zero-valent metals to reduce chlorinated organics has some drawbacks. For example, even if nanoscale zero-valent iron particles are used, the metal mass normalized observed rate constant for dechlorination of chlorinated organics is still very low

\footnotetext{
* Corresponding author. Tel.: +86 10 62849194; fax: +861062923564.

E-mail address: zpinghao@rcees.ac.cn (Z. Hao).
}

[8]. More important is that a hydroxide or oxide layer forms on the metal particle surface during the reaction, significantly decreases the effective use of the metal particles. Further efforts to improve the performance of the zero-valent metal technology were the use of bimetallic nanoparticles such as $\mathrm{Pd} / \mathrm{Fe}, \mathrm{Pd} / \mathrm{Mg}$. The introduction of catalytic metal Pd could increase surface area, enhance the formation of atomic hydrogen or hydride on the surface and inhibit the corrosion products from accumulating on the surface reactive sites of zero-valent metal [9]. However, high expense of Pd noble metal limits its wide application for pollutant treatment.

There are number of studies demonstrating successful dechlorination of chlorinated compounds like trichloroethylene (TCE) [8], pentachlorophenol (PCP) [10] and carbon tetrachloride $\left(\mathrm{CCl}_{4}\right)$ [11] by $\mathrm{Ni} / \mathrm{Fe}$ nanoparticles. The proposed mechanism is that the catalytic nickel enhances the formation of atomic hydrogen or hydride on the surface and alters the electronic properties of the iron. Then $\mathrm{C}-\mathrm{Cl}$ bond of adsorbed chlorinated compound onto the surface of the $\mathrm{Ni} / \mathrm{Fe}$ nanoparticles is broken, and the chlorine atom is replaced by hydrogen $[8,12]$. The reaction process can be represented as follows:

$$
\begin{aligned}
& \mathrm{Fe}^{0} \rightarrow \mathrm{Fe}^{2+}+2 \mathrm{e}^{-} \\
& 2 \mathrm{H}_{2} \mathrm{O}+2 \mathrm{e}^{-} \stackrel{\mathrm{Ni}}{\longrightarrow} 2 \mathrm{H}^{*}+2 \mathrm{OH}^{-} \\
& \mathrm{Ni}+\mathrm{H} * \rightarrow \mathrm{Ni}-\mathrm{H} \\
& \mathrm{Ni}-\mathrm{H}+\mathrm{R}-\mathrm{Cl} \rightarrow \mathrm{Ni}+\mathrm{R}-\mathrm{H}+\mathrm{Cl}^{-}
\end{aligned}
$$


The above equations indicate that $\mathrm{pH}$ value is a crucial parameter that affects the degradation rate of chlorinated compounds. At higher $\mathrm{pH}$, less atomic hydrogen or hydride on the catalyst surface attacks chlorinated molecules to replace the chlorine atom and to form dechlorinated molecule and chlorine ion. Meanwhile, the ferrous and hydroxyl ions form ferrous hydroxide and precipitate. The surface passivating layer of the ferrous hydroxide and precipitate could hinder the transport of the chlorinated molecules and block the reactive sites on $\mathrm{Ni} / \mathrm{Fe}$ and hence depress the overall reaction rate [13].

Chen's study verified the kinetic model for the dechlorination reaction by using bimetallic $\mathrm{Ni} / \mathrm{Fe}$ is a pseudo first-order treatment of the parent compound [13]:

$-\frac{\mathrm{d} C}{\mathrm{~d} t}=k_{\mathrm{SA}} \alpha_{\mathrm{S}} \rho_{\mathrm{m}} C$

where $C$ represents the concentration of chlorinated compound, $k_{\mathrm{SA}}$ is the specific reaction rate constant $\left(\mathrm{L} / \mathrm{h} \mathrm{m}^{2}\right), \alpha_{\mathrm{S}}$ is the specific surface area of $\mathrm{Ni} / \mathrm{Fe}\left(\mathrm{m}^{2} / \mathrm{g}\right)$, and $\rho_{\mathrm{m}}$ is the mass concentration of $\mathrm{Ni} / \mathrm{Fe}(\mathrm{g} / \mathrm{L})$. Variations in the $k_{\mathrm{SA}}$ value were attributed to impurities within the metal matrix, which can affect the distribution of active sites [12]. The value of $k_{\mathrm{SA}}$ reported by Schrick et al. for TCE dechlorination using Ni/Fe nanoparticles $(1: 3.4 \mathrm{Ni} / \mathrm{Fe}$ ratio) is $9.8 \times 10^{-2} \mathrm{~L} / \mathrm{h} \mathrm{m}^{2}$, which is much higher compared to $2.0 \times 10^{-3} \mathrm{~L} / \mathrm{h} \mathrm{m}^{2}$ for nanoiron [8]. Tee et al. [14] found that a maximum rate of dechlorination is achieved with a Ni content of $25 \mathrm{wt} \%$, similar to the Ni/Fe ratio designed by Schrick et al. [8] to obtain the faster TCE dechlorination rate. The decrease in reaction rates as the Ni content increase beyond this level is attributed to high levels of $\mathrm{Ni}$ with respect to $\mathrm{Fe}$ at the particle edges, which hinder the ability of Fe to transfer electrons to the reaction sites.

The objective of this work is to study the degradation of DDT using bimetallic Ni/Fe nanoparticles, which has not been reported to our knowledge. 1:3.5 was chosen for $\mathrm{Ni} / \mathrm{Fe}$ ratio. The effect of $\mathrm{pH}$ on the degradation of DDT using Ni/Fe nanoparticles is investigated. Furthermore, the mechanism of DDT degradation is also proposed.

\section{Experimental}

\subsection{Materials}

p, $\mathrm{p}^{\prime}$-DDT was purchased from Aldrich. Calibration standards of DDTs, including p,p'-DDE, p,p'-DDD and p,p'-DDT that obtained from AccuStandard, Inc., were prepared by dissolving the mix in n-hexane, then stored in polytetrafluoroethylene-lined screw cap vials at $4{ }^{\circ} \mathrm{C}$. n-Hexane (HPLC) was offered by J\&K Chemical Ltd. The other chemicals used: ferrous sulfate $\left(\mathrm{FeSO}_{4} \cdot 7 \mathrm{H}_{2} \mathrm{O}\right.$, Beijing Chemical Reagent Factory, China), nickel nitrate $\left(\mathrm{Ni}\left(\mathrm{NO}_{3}\right)_{2} \cdot 6 \mathrm{H}_{2} \mathrm{O}\right.$, Beijing Shuanghuan Chemical Reagent Factory, China), potassium borohydride $\left(\mathrm{KBH}_{4}\right.$, Tianjin Jinke Fine Chemical Research Institute, China). Sodium sulfate ( $\mathrm{Na}_{2} \mathrm{SO}_{4}$, Beijing Chemical Reagent Factory, China) was oven-dried at $150^{\circ} \mathrm{C}$ for $2 \mathrm{~h}$ to act as a desiccant. All solutions were prepared in ultrapure water $(R=18 \mathrm{~m} \Omega)$.

\subsection{Synthesis of $\mathrm{Ni} / \mathrm{Fe}$ nanoparticles}

$\mathrm{Ni} / \mathrm{Fe}$ nanoparticles were synthesized by modifying the method described by Schrick et al. [8]. $0.03 \mathrm{~g} \mathrm{FeSO}_{4} \cdot 7 \mathrm{H}_{2} \mathrm{O}$ and $0.009 \mathrm{~g}$ $\mathrm{Ni}\left(\mathrm{NO}_{3}\right)_{2} \cdot 6 \mathrm{H}_{2} \mathrm{O}(\mathrm{Ni} / \mathrm{Fe}$ molar ratio is $1: 3.5)$ were dissolved in $75 \mathrm{~mL}$ of ultrapure water with shaking by hands. Then the salts were reduced to black particles by adding dropwise a certain amount of $\mathrm{KBH}_{4}$ solution $\left(\mathrm{BH}_{4}{ }^{-} / \mathrm{M}^{2+}=3, \mathrm{M}\right.$ represents as $\mathrm{Fe}$ or $\left.\mathrm{Ni}\right)$. The $\mathrm{KBH}_{4}$ amount was excessive to ensure all of salts reduced. The zerovalent iron nanoparticles were synthesized by the same method.
No special precautions were taken to eliminate oxygen from the reaction vessel. After shaking for $20 \mathrm{~min}$, the mixture was centrifuged, washed with ultrapure water for several times, and rinsed by ethanol. At last, the particles were collected and stored in ethanol for subsequent experiments.

\subsection{Characterization of $\mathrm{Ni} / \mathrm{Fe}$ nanoparticles}

Transmission Electron Microscope (TEM) images were obtained using a Hitachi H-7500 microscope. A typical TEM sample was prepared by depositing several droplets of the nanoparticles/ethanol mixture onto a carbon-coated Cu-grid.

\subsection{DDT degradation studies}

DDT stock solution $(100 \mu \mathrm{g} / \mathrm{mL})$ was prepared in analyticalgrade acetone, and diluted with a water-acetone solution, which had been deoxygenated by purging $\mathrm{N}_{2}$ for $1 \mathrm{~h}$. The final water-acetone ratio was adjusted to 9:1 (v/v) using water or acetone, referential to Gautam's study [15]. $150 \mathrm{~mL}$ of DDT solution with desired concentration was then added into a $150-\mathrm{mL}$ glass reactor. Reaction was initiated by the addition of zero-valent metals $(0.05 \mathrm{mg} / \mathrm{mL})$. All experiments were conducted in nitrogen atmosphere, with constant stirring.

At predetermined time intervals, $10 \mathrm{~mL}$ suspension was sacrificed and extracted with $4 \mathrm{~mL}$ n-hexane to recover DDT. After passing though a glass column containing about $1 \mathrm{~g}$ anhydrous sodium sulfate $\left(\mathrm{Na}_{2} \mathrm{SO}_{4}\right)$ and diluted for four times, about $1 \mathrm{~mL}$ aliquots from the diluted hexane extracts were removed in $2 \mathrm{~mL}$ glass vials. The vials were immediately sealed with Teflon-lined septa caps and later analyzed for DDT and its degradation products using GC-MS.

To investigate $\mathrm{pH}$ effect, the degradation experiments were carried out at an initial $\mathrm{pH}$ ranging from 2 to 12 adjusted with $\mathrm{NaOH}$ or $\mathrm{HCl}$.

\subsection{GC-MS analysis}

GC-MS analysis was conducted on an Agilent 6890 gas chromatograph equipped with an Agilent 5973 mass selective detector. An HP-5 capillary column $(0.25 \mu \mathrm{m}, 0.25 \mathrm{~mm} \times 30 \mathrm{~m})$ was used. Ultrahigh purity helium (flow rate of $1.0 \mathrm{~mL} / \mathrm{min}$ ) was used as the carrier gas. The injection volume was $1 \mu \mathrm{L}$. The column temperature was ramped as follows: initial temperature of $70^{\circ} \mathrm{C}$ was kept for $2 \mathrm{~min}$ following the injection, increased by $20^{\circ} \mathrm{C} / \mathrm{min}$ to $200^{\circ} \mathrm{C}$ and by $10^{\circ} \mathrm{C} / \mathrm{min}$ to $280^{\circ} \mathrm{C}$, and maintained at the final temperature for $1.5 \mathrm{~min}$. The net run time for the analysis was $18 \mathrm{~min}$. The identification and quantification of DDT and its metabolites were done using selective ion monitoring.

\section{Results and discussion}

\subsection{Characterization of materials}

Fig. 1 shows TEM of the monometallic zero-valent iron and bimetallic Ni/Fe nanoparticles. The synthesized particles are both approximately spherical, and form chains of beads, especially for monometallic zero-valent iron. This type of aggregation is attributed to magnetic interaction between the primary metal particles [16]. The Ni/Fe particles are in the range of $80-140 \mathrm{~nm}$ in diameter, smaller than the particles of zero-valent iron $(145-230 \mathrm{~nm})$. We propose that the addition of $\mathrm{Ni}$ could limit the nanocrystalline growth of Fe and decrease the particle size of $\mathrm{Ni} / \mathrm{Fe}$. 

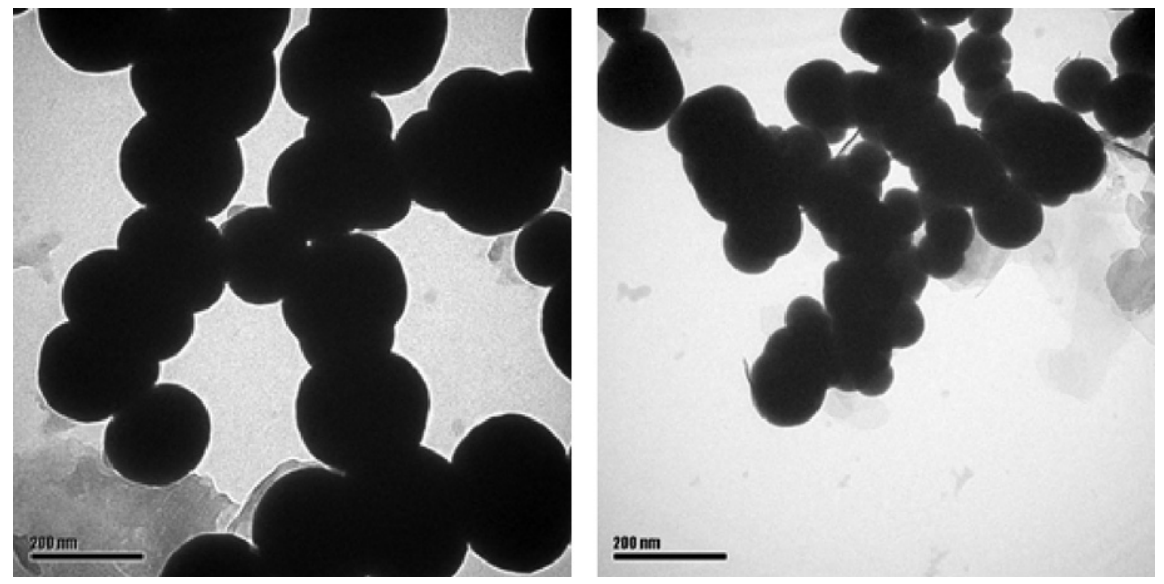

Fig. 1. TEM of Fe (left) and Ni/Fe (right) nanoparticles.

\subsection{Effect of materials on DDT degradation}

Although the excellent degradation rates of DDT using zerovalent iron nanoparticles were reported before [17,18], the rate of DDT degradation using bimetallic Ni/Fe nanoparticles is evidently faster than that using zero-valent iron (Fig. 2), indicating that the presence of $\mathrm{Ni}$ promotes the degradation reaction of DDT as the action on other chlorinated compounds such as TCE and PCP. Fig. 2 shows that almost $90 \%$ of DDT degrades within $4 \mathrm{~h}$.

\subsection{Effect of initial $\mathrm{pH}$ on DDT degradation}

The concentration profiles for DDT degradation using Ni/Fe nanoparticles at different $\mathrm{pH}$ values are shown in Fig. 3. Over 85\% degradation of DDT can be obtained in $8 \mathrm{~h}$, except the experiment at elevated $\mathrm{pH} 12$.

To describe the initial kinetics of DDT degradation, the firstorder rate constants $\left(k_{\text {obs }}\right)$ derived from Eq. (5) is used (Table 1 ):

$\rho_{\mathrm{a}}=\alpha_{\mathrm{s}} \rho_{\mathrm{m}}$

$k_{\mathrm{obs}}=k_{\mathrm{SA}} \rho_{\mathrm{a}}$

$-\frac{\mathrm{d} C}{\mathrm{~d} t}=k_{\mathrm{obs}} C_{0}$

or

$k_{\mathrm{obs}} t=\ln \left(\frac{C}{C_{0}}\right)$

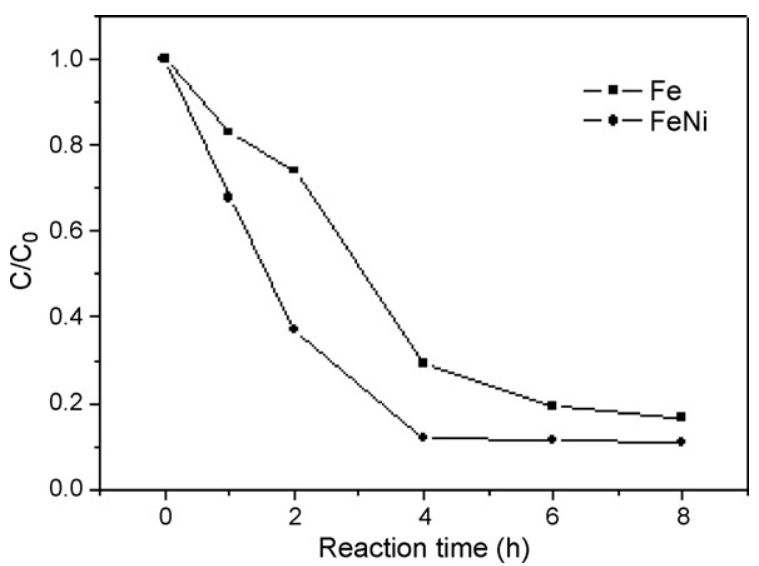

Fig. 2. Degradation of DDT in aqueous solution using Fe only and bimetallic $\mathrm{Ni} / \mathrm{Fe}$ nanoparticles $\left(C_{0}=1.09 \mu \mathrm{g} / \mathrm{mL}\right.$, Fe or Ni/Fe: $0.05 \mathrm{mg} / \mathrm{mL}$, pH 7).

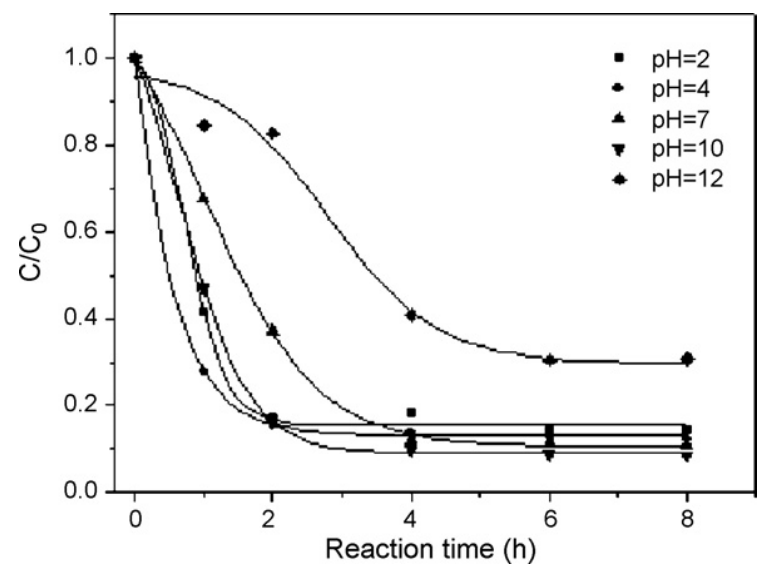

Fig. 3. Effect of $\mathrm{pH}$ value on the degradation of DDT in aqueous solution using $\mathrm{Ni} / \mathrm{Fe}$ nanoparticles $\left(C_{0}=1.09 \mu \mathrm{g} / \mathrm{mL}, \mathrm{Ni} / \mathrm{Fe}: 0.05 \mathrm{mg} / \mathrm{mL}\right)$.

Where $\rho_{\mathrm{a}}$ is the surface area concentration of $\mathrm{Ni} / \mathrm{Fe}\left(\mathrm{m}^{2} / \mathrm{L}\right)$, and $C_{0}$ is the initial concentration of DDT.

$k_{\text {obs }}(2)$ and $k_{\text {obs }}(4)$ are used to represent the first-order rate constants within $2 \mathrm{~h}$ and $4 \mathrm{~h}$, respectively. Fig. 3 and Table 1 show that at initial $\mathrm{pH}$ values below 7 , the $k_{\mathrm{obs}}$ value decreases with $\mathrm{pH}$ at the reaction time of either $2 \mathrm{~h}$ or $4 \mathrm{~h}$. The slow degradation rate is attributed to the fast disappearance of zero-valent iron due to iron corrosion. With extending the reaction time from $2 \mathrm{~h}$ to $4 \mathrm{~h}$, the $k_{\text {obs }}$ at $\mathrm{pH} 10$ becomes higher than at $\mathrm{pH} 4$. It is known that the ferrous and hydroxyl ions generally form ferrous hydroxide and precipitate at higher $\mathrm{pH}$. The precipitation of ferrous hydroxide on the surface of zero-valent iron could hinder the transport of the chlorinated molecules and decrease the reaction rate [13]. However, in our experiment, faster degradation rate of DDT at $\mathrm{pH} 10$ than at $\mathrm{pH} 4$ is obtained at reaction time of $4 \mathrm{~h}$. The reason for this could be the increase of dehydrochlorination reaction rate at higher $\mathrm{pH}$ value ( $\mathrm{pH} \geq 10$, as shown in Fig. 4).

Fig. 4 shows the degradation of DDT and its metabolites as a function of time at different $\mathrm{pH}$ values. The presence of the metabolites

Table 1

Apparent rate constant, $k_{\text {obs }}$ for DDT degradation using $\mathrm{Ni} / \mathrm{Fe}$ at different initial $\mathrm{pH}$ value.

\begin{tabular}{llllll}
\hline$k_{\text {obs }}$ & $\mathrm{pH}$ & & & & \\
\cline { 2 - 6 } & 2 & 4 & 7 & 10 & 12 \\
\hline$k_{\text {obs }}(2)\left(\mathrm{h}^{-1}\right)$ & 0.8938 & 0.9697 & 0.4739 & 0.8819 & 0.1088 \\
$k_{\text {obs }}(4)\left(\mathrm{h}^{-1}\right)$ & 0.535 & 0.6073 & 0.5183 & 0.6517 & 0.1971 \\
\hline
\end{tabular}



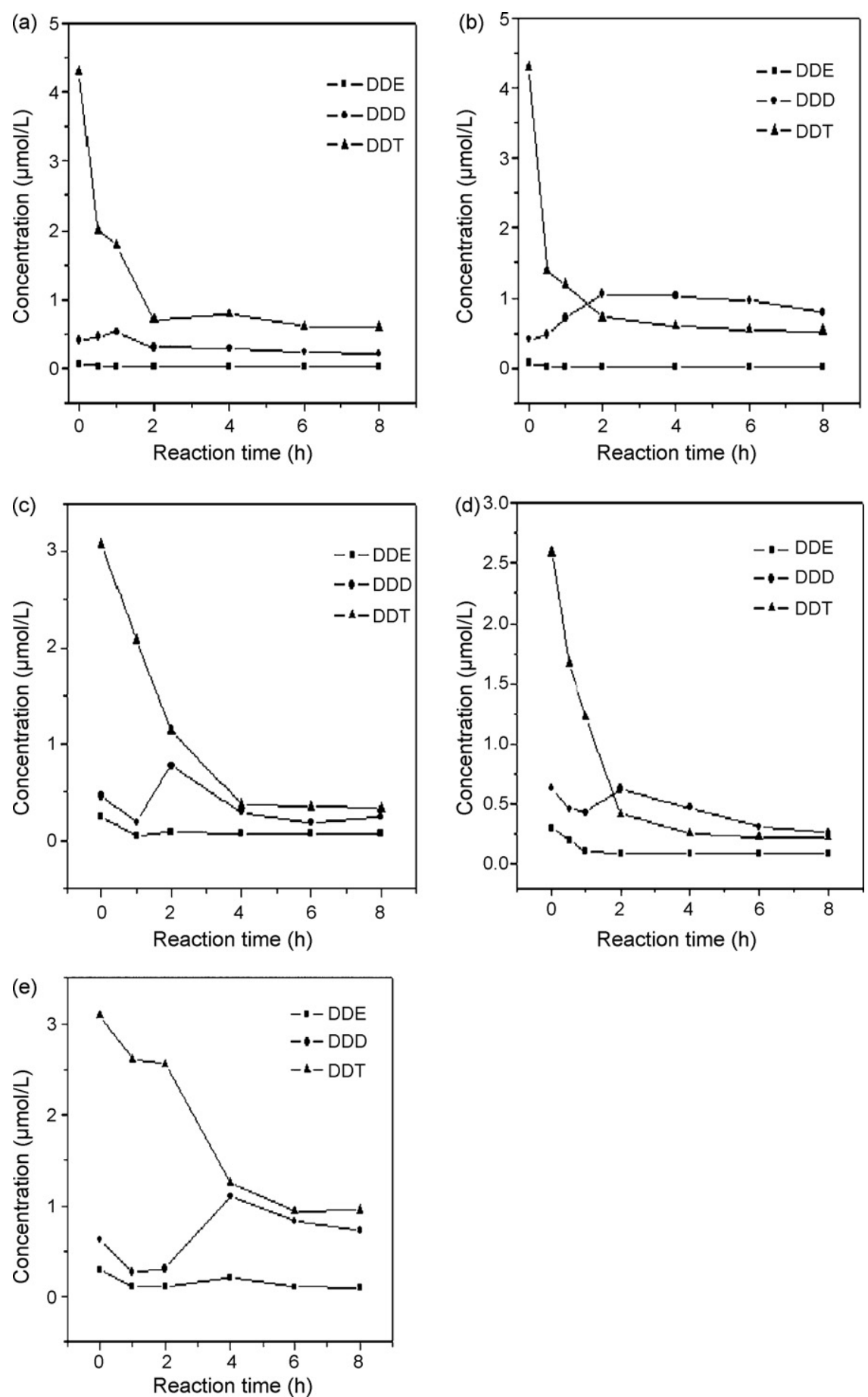

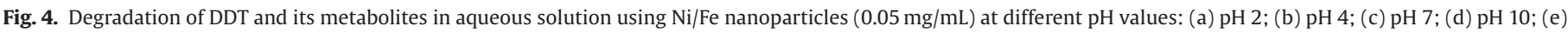
$\mathrm{pH} 12$.

DDD and DDE at the reaction time of $0 \mathrm{~h}$ is because of the impurity of DDT stock material. The results indicate that the main metabolite of DDT using Ni/Fe nanoparticles is DDD. But the dehydrochlorination reaction rate after $2 \mathrm{~h}$ at higher $\mathrm{pH}(\mathrm{pH} 12)$ increases, which is unexpected. The proposed reason and main reaction mechanism will be discussed in the following section.

The trends of DDT and its metabolites with the proceeding of the reaction shown in Fig. 4 also indicates that the DDD concentration is maximized at reaction time between $1 \mathrm{~h}$ and $4 \mathrm{~h}$, and then slowly decreases during the later reaction stages. At initial $\mathrm{pH}$ value ranging from 4 to 10 , DDD concentration maximizes at the reaction time of $2 \mathrm{~h}$, and $4 \mathrm{~h}$ at $\mathrm{pH} 12$. This suggests that too high $\mathrm{pH}$ seems to be detrimental for the DDD degradation, but not quench the degradation, as in the case of the DDT degradation. It might be deduced that the degradation mechanism of DDD at different $\mathrm{pH}$ values is similar with that of DDT. The shortest time when DDD reaches the maximum amount is $1 \mathrm{~h}$ at $\mathrm{pH} 2$, but the increased extent of DDD concentration is the minimum, indicating the slow degradation of DDT to DDD.

\subsection{Degradation mechanism of trichloromethyl group of DDT}

As we know, DDT can be transformed into DDD and DDE by hydrodechlorination and dehydrochlorination pathways, respec- 


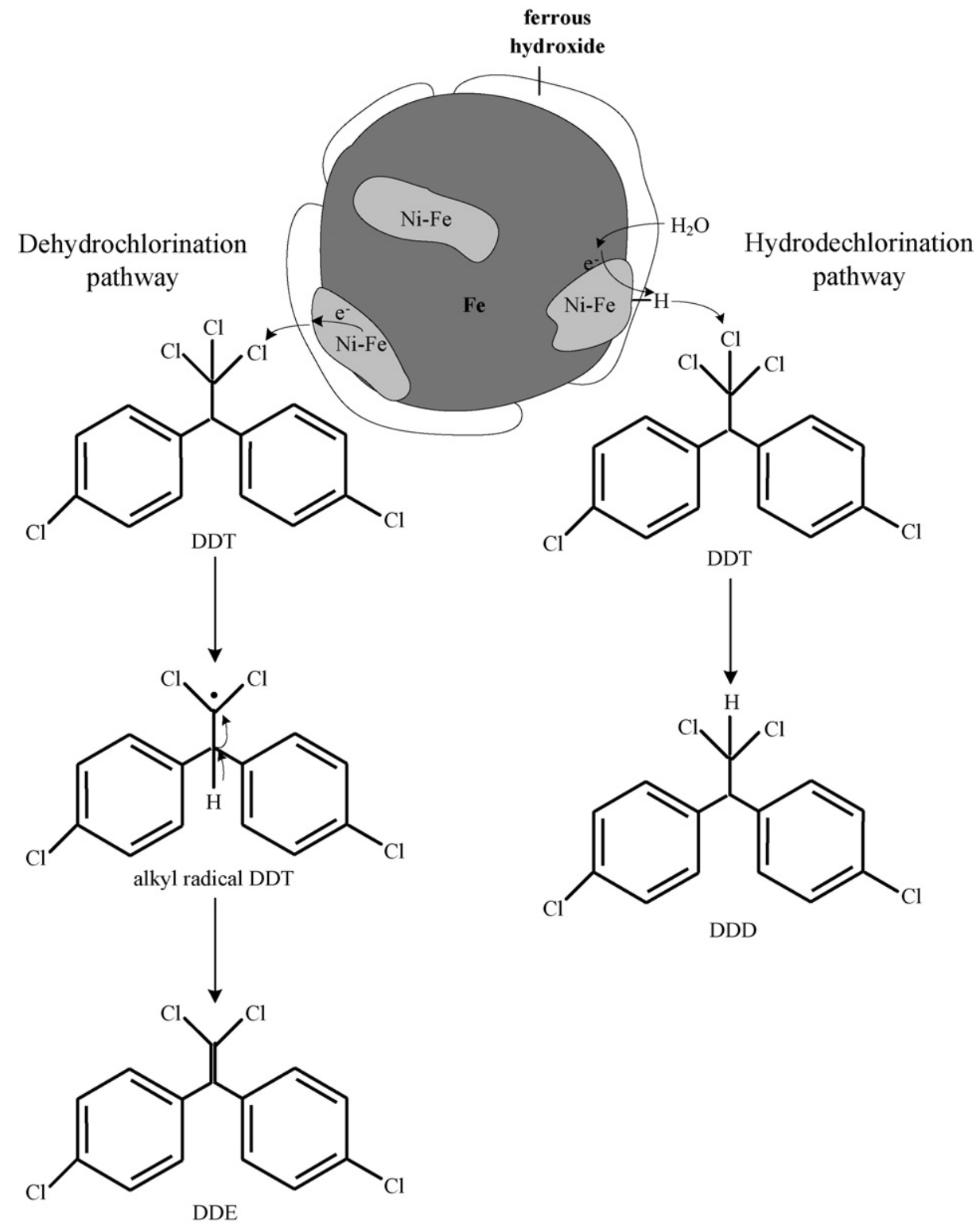

Fig. 5. Tentative degradation mechanism of trichloromethyl group of DDT.

tively. Laboratory researches showed that the hydrodechlorination pathway happens under neutral or acidic condition using zerovalent metals and bimetallic systems, higher $\mathrm{pH}$ could quench the hydrodechlorination reaction of DDT [15,17]. Sayles et al. [17] reported that no transformations of DDT were observed in reactors with addition of $25 \mathrm{mM} \mathrm{NaOH}$ and zero-valent iron. It is known that the dehydrochlorination reaction is almost impossible in alkaline aqueous solution without alcohols or heating $[19,20]$. However, in our work, the dehydrochlorination reaction apparently occurred at higher $\mathrm{pH}$ values, we estimate this could be due to the promoting function of $\mathrm{Ni}$.

The proposed degradation mechanism is shown in Fig. 5. In alkaline condition, the ferrous hydroxide forms and deposits on the surface of zero-valent iron, and numerous analogously galvanic cells can be created between ferrous hydroxide and zero-valent iron under the catalysis of $\mathrm{Ni}$ [21]. This may enhance the electron transfer from zero-valent iron to DDT. In the dehydrochlorination pathway, after abstracting single electron, a chloride anion and an alkyl radical DDT are obtained since the reductive cleavage of aliphatic halides does not afford anion radicals as discrete intermediates [22]. Subsequently, the alkyl radical DDT loses the hydrogen at the benzylic position to form DDE. Meanwhile, a hydrogen chloride produces and is scavenged by $\mathrm{NaOH}$ to form $\mathrm{NaCl}$, which also promotes the dehydrochlorination rate. In the hydrodechlorination pathway, similarly to the process in acidic solution, $\mathrm{H}_{2} \mathrm{O}$ abstracts electrons and is reduced to adsorbed hydrogen on the catalytic $\mathrm{Ni}$ surface. DDT is adsorbed onto the surface of the Ni/Fe nanoparticles where the $\mathrm{C}-\mathrm{Cl}$ bond is broken, and the chlorine atom is replaced by hydrogen. It can be seen that the significant difference is that the electrons come from galvanic cells between ferrous hydroxide and iron in alkaline condition, whereas the electrons in acidic and neutral solution are obtained by iron corrosion.

\section{Conclusions}

Bimetallic Ni/Fe nanoparticles were synthesized and used in the DDT degradation studies. The DDT degradation rate using bimetallic $\mathrm{Ni} / \mathrm{Fe}$ nanoparticles is evidently faster than that using monometallic zero-valent iron, over 90\% of DDT is transformed within $4 \mathrm{~h}$ in neutral condition. First-order rate constants $\left(k_{\mathrm{obs}}\right)$ based on the pseudo first-order reaction model is determined to explore the effects of $\mathrm{pH}$ value on the degradation rate in bimetallic $\mathrm{Ni} / \mathrm{Fe}$ system. The results 
show that the degradation rate is highly $\mathrm{pH}$ dependent. Because the disappearance of zero-valent iron by iron corrosion could be accelerated in acidic condition and the ferrous hydroxide and precipitate are produced at higher $\mathrm{pH}$, weaker acid $(4 \leq \mathrm{pH}<7)$ and alkaline $(7<\mathrm{pH} \leq 10)$ reaction conditions are more favorable to fast degradation of DDT in aqueous solution. In addition, the $\mathrm{pH}$ value also influences the degradation mechanism. Higher $\mathrm{pH}$ does not quench the DDT degradation, but promotes the dehydrochlorination reaction, which is mainly due to the formation of galvanic cells under the catalysis of Ni to enhance the electron transfer. The hydrodechlorination reaction in alkaline condition is also unbroken with the electrons transfer of galvanic cells between ferrous hydroxide and iron.

\section{Acknowledgements}

This research was financially supported by the National High Technology Research and Development Program of China (2006AA06A310) and National Science Fund for Distinguished Young Scholar (20725723) is gratefully acknowledged. The authors thank three anonymous reviewers for their insightful comments.

\section{References}

[1] UNEP, Homepage of the Stockholm Convention on Persistent Organic Pollutants, http://www.pops.int.

[2] X.L. Yang, S.S. Wang, Y.R. Bian, F. Chen, G.F. Yu, C.G. Gu, X. Jiang, Dicofol application resulted in high DDTs residue in cotton fields from northern Jiangsu province, China, J. Hazard. Mater. 150 (2008) 92-98.

[3] L.A. Totten, C.L. Gigliotti, J.H. Offenberg, J.E. Baker, S.J. Eisenreich, Reevaluation of air-water exchange fluxes of PCBs in green bay and southern lake michigan, Environ. Sci. Technol. 37 (2003) 1739-1743.

[4] G.L. Daly, Y.D. Lei, C. Teixeira, D.C.G. Muir, L.E. Castillo, L.M.M. Jantunen, F. Wania, Organochlorine pesticides in the soils and atmosphere of costa rica, Environ. Sci. Technol. 41 (2007) 1124-1130.

[5] J.F. Quensen III, S.A. Mueller, M.K. Jain, J.M. Tiedje, Reductive dechlorination of DDE to DDMU in marine sediment microcosms, Science 280 (1998) 722-724.

[6] C. Lin, K.S. Lin, Photocatalytic oxidation of toxic organohalides with $\mathrm{TiO}_{2} / \mathrm{UV}$ : the effects of humic substances and organic mixtures, Chemosphere 66 (2007) 1872-1877.
[7] S.S. Zinovyev, N.A. Shinkovaa, A. Perosa, P. Tundo, Liquid phase hydrodechlorination of dieldrin and DDT over Pd/C and Raney-Ni, Appl. Catal. B 55 (2005) 39-48.

[8] B. Schrick, J.L. Blough, A.D. Jones, T.E. Mallouk, Hydrodechlorination of trichloroethylene to hydrocarbons using bimetallic nickel-iron nanoparticles, Chem. Mater. 14 (2002) 5140-5147.

[9] A.D. Bokare, R.C. Chikate, C.V. Rode, K.M. Paknikar, Effect of surface chemistry of $\mathrm{Fe}-\mathrm{Ni}$ nanoparticles on mechanistic pathways of azo dye degradation, Environ. Sci. Technol. 41 (2007) 7437-7443.

[10] W.H. Zhang, X. Quan, J.X. Wang, Z.Y. Zhang, S. Chen, Rapid and complete dechlorination of PCP in aqueous solution using $\mathrm{Ni}-\mathrm{Fe}$ nanoparticles under assistance of ultrasound, Chemosphere 65 (2006) 58-64.

[11] J. Feng, T.T. Lim, Pathways and kinetics of carbon tetrachloride and chloroform reductions by nano-scale $\mathrm{Fe}$ and $\mathrm{Fe} / \mathrm{Ni}$ particles: comparison with commercial micro-scale Fe and Zn, Chemosphere 59 (2005) 1267-1277.

[12] W.Arnold, A.L. Rpnerts, Pathways and kinetics of chlorinated ethylene and chlorinated acetylene reaction with $\mathrm{Fe}(0)$ particles, Environ. Sci. Technol. 34 (2000) 1794-1805.

[13] J.L. Chen, S.R. Al-Abed, J.A. Ryan, Z.B. Li, Effects of pH on dechlorination of trichloroethylene by zero-valent iron, J. Hazard. Mater. 83 (2001) 243-254.

[14] Y.H. Tee, E. Grulke, D. Bhattacharyya, Role of Ni/Fe nanoparticle composition on the degradation of trichloroethylene from water, Ind. Eng. Chem. Res. 44 (2005) $7062-7070$.

[15] S.K. Gautam, S. Suresh, Studies on dechlorination of DDT (1,1,1-trichloro-2,2bis(4-chlorophenyl)ethane) using magnesium/palladium bimetallic system, J. Hazard. Mater. 139 (2007) 146-153.

[16] L. Zhang, A. Manthiram, Chains composed of nanosize metal particles and identifying the factors driving their formation, Appl. Phys. Lett. 70 (1997) 2469-2471.

[17] G.D. Sayles, G. You, M. Wang, M.J. Kuperferle, DDT, DDD, and DDE dechlorination by zero-valent iron, Environ. Sci. Technol. 31 (1997) 3448-3454.

[18] T. Eggen, A. Majcherczyk, Effects of zero-valent iron $\left(\mathrm{Fe}^{0}\right)$ and temperature on the transformation of DDT and its metabolites in lake sediment, Chemosphere 62 (2006) 1116-1125

[19] S.J. Cristol, A kinetic study of the dehydrochlorination of substituted 2,2-diphenylchloroethanes related to DDT, J. Am. Chem. Soc. 67 (1945) 1494-1498.

[20] Y. Ukisu, Complete dechlorination of DDT and its metabolites in an alcohol mixture using $\mathrm{NaOH}$ and $\mathrm{Pd} / \mathrm{C}$ catalyst, J. Hazard. Mater. 152 (2008) 287-292.

[21] Y.L. Nie, C. Hu, J.H. Qu, L. Zhou, X.X. Hu, Photoassisted degradation of azodyes over $\mathrm{FeO}_{x} \mathrm{H}_{2 x-3} / \mathrm{Fe}^{0}$ in the presence of $\mathrm{H}_{2} \mathrm{O}_{2}$ at neutral $\mathrm{pH}$ values, Environ. Sci. Technol. 41 (2007) 4715-4719.

[22] C.P. Andrieux, J.M. Saveant, K.B. Su, Kinetics of dissociative electron transfer Direct and mediated electrochemical reductive cleavage of the carbon-halogen bond, J. Phys. Chem. 90 (1986) 3815-3823. 